\title{
OPTIMALISASI BIAYA DAN WAKTU PELAKSANAAN PROYEK PEMBANGUNAN PERUMAHAN CITRALAND PALU MENGGUNAKAN METODE PROGRAM EVALUATION AND REVIEW TECHNIQUE (PERT) - CRITICAL PATH METHOD (CPM)
}

\author{
N. M. E. Wardani' ${ }^{1}$ S. Musdalifah², dan D. Lusiyanti ${ }^{3}$ \\ 1,2,3Program Studi Matematika Jurusan Matematika FMIPA Universitas Tadulako \\ Jalan Soekarno-Hatta Km. 09 Tondo, Palu 94118, Indonesia. \\ 1erniwardani42@yahoo.com, 2Selvymusdalifah@yahoo.com, 3Desylusiyanti@Gmail.com.
}

\begin{abstract}
This study aimed to optimize the cost and time of implementation of development projects in residential homes Citraland located in the town of Palu subdistrict villages Mantikulore Tondo. Completion of construction of residential houses has been delayed time of completion of the construction. This leads to greater costs incurred in development projects. Therefore, to solve these problems is necessary to analyze the optimization of project time to determine how long a project is completed. Optimization of costs and project execution time is calculated using the Critical Path Method (CPM). The method is based on the results obtained, namely the normal completion time of the project for 69 weeks with a total cost of Rp. 297,887,212.00. Aftertime optimization through crashing eachthe implementation of the activities of the development to 48 weeks with a total cost of Rp. 350,261,175.00. The probability of completion of project design development using methods Program Evolution and Review Technique (PERT) is great opportunity to complete the project work for 48 weeks amounted to $93.19 \%$
\end{abstract}

Keywords : Cost, Project Design Development, PERT-CPM, Time

\section{ABSTRAK}

Penelitian ini bertujuan untuk mengoptimalkan biaya dan waktu pelaksanaan proyek pembangunan rumah tinggal di perumahan Citraland yang berlokasi di kota Palu kelurahan Tondo kecamatan Mantikulore. Penyelesaian pembangunan rumah tinggal mengalami keterlambatan waktu penyelesaian pembangunan. Hal ini menyebabkan biaya semakin besar yang dikeluarkan dalam proyek pembangunan. Oleh karena itu untuk menyelesaikan masalah tersebut diperlukan analisis optimalisasi waktu proyek untuk mengetahui berapa lama suatu proyek tersebut diselesaikan. Optimalisasi biaya dan waktu pelaksanaan proyek dihitung menggunakan metode Critical Path Method (CPM). Berdasarkan metode tersebut hasil yang didapatkan yaitu waktu penyelesaian normal proyek selama 69 minggu dengan total biaya sebesar Rp. 297.887.212,00. Setelah dilakukan pengoptimalan waktu melalui crashing setiap kegiatan pelaksanaan pembangunan tersebut menjadi 48 minggu dengan total biaya Rp. 350.261.175,00 . Dari probabilitas penyelesaian rancangan proyek pembangunan menggunakan metode Program Evolution and Review Technique (PERT) besar peluang untuk menyelesaikan pekerjaan proyek selama 48 minggu adalah sebesar $93.19 \%$

Kata Kunci : Biaya, Rancangan Proyek Pembangunan, PERT-CPM, Waktu 


\section{PENDAHULUAN}

\subsection{Latar Belakang}

Indonesia merupakan negara yang berkembang, memiliki banyak penduduk dengan pertumbuhan yang sangat cepat. Hal tesebut mengakibatkan kebutuhan akan rumah tinggal di Indonesia sangat tinggi. Dalam pembangunan rumah tinggal perlu adanya manajemen penjadwalan kerja yang baik, dengan perhitungan biaya yang cermat dan teliti agar pembangunan dapat terselesaikan dengan efisien. Suatu pembangunan dikatakan efisien jika dapat mengoptimalkan sumber daya yang ada seperti waktu dan biaya, serta meminimalkan kendala-kendala yang mungkin terjadi dalam suatu pembangunan. (Ade Saparudin, 2014).

Pembangunan merupakan suatu proses yang melalui beberapa kegiatan dalam mambangun dan dilakukan secara terus menerus pada suatu wilayah untuk memperbaiki indikator sosial maupun ekonomi suatu wilayah dari waktu ke waktu. Disamping itu juga pembangunan merupakan pengembangan daerah-daerah yang ada di Indonesia, salah satunya dikota Palu. Daerah kota Palu yang dalam proses pengembangan dan masih banyak lahan yang belum terpakai sangat diminati oleh investor untuk mengembangkan sektor pembangunan dan perdagangan.

Perkembangan ini ditandai dengan dibangunnya bangunan dan wahana yang modern, salah satunya adalah perumahan citraland yang dibangun di area kota Palu bagian Tondo. Dibangunnya perumahan citraland di kota Palu ini untuk memajukan perkembangan kota Palu agar lebih berkembang lagi dan memberi rasa nyaman berpenghuni di kota Palu. Citraland, waterfront city memiliki lokasi yang sangat strategis di jalan Trans Sulawesi, sebagai ring road penghubung pusat kota Palu dan Makassar. Kawasan ini memiliki masterplan prestisius seluas 20 hektar di tepi pantai teluk Palu yang indah.

Pada saat ini perusahaan menginginkan proyek pembangunan rumah tinggal selesai lebih cepat dari rencana proyek pembangunan, karena hal ini akan mempengaruhi keuntungan perusahaan dari hasil penjualan rumah tinggal. Untuk menangani hal tersebut diperlukan suatu upaya mempercepat waktu pekerjaan proyek walaupun akan meningkatnya biaya proyek. Waktu percepatan pembangunan ditentukan oleh perusahaan, sehingga diperlukan analisis optimalisasi waktu proyek untuk mengetahui berapa lama suatu proyek tersebut diselesaikan. Pada penelitian ini akan mengoptimalisasi biaya dan waktu pada proyek pembangunan rumah tinggal di perumahan Citraland dengan menggunakan metode Project Evaluation and Review Technique (PERT) dan Critical Path Method (CPM). 


\subsection{Rumusan Masalah}

Berdasarkan latar belakang di atas dapat dirumuskan masalah yang akan diteliti yaitu :

1. Bagaimana penyusunan diagram jaringan kerja pada proyek pembangunan rumah tinggal di perumahan Citraland Palu menggunakan metode Critical Path Method Project Evaluation and Review Technique

2. Berapakah waktu dan biaya optimal yang dibutuhkan dalam penyelesaian proyek pembangunan rumah tinggal di perumahan Citraland Palu menggunakan metode Critical Path Method

\subsection{Tujuan}

Adapun tujuan dari penelitian ini yaitu :

1. Mendapatkan penyusunan diagram jaringan kerja pada proyek pembangunan rumah tinggal di perumahan Citraland Palu menggunakan metode Critical Path Method Project Evaluation and Review Technique

2. Mendapatkan waktu dan biaya optimal yang dibutuhkan dalam penyelesaian proyek pembangunan rumah tinggal diperumahan Citraland Palu menggunakan metode Critical Path Method

\section{METODE PENELITIAN}

Metode data penelitian ini dilakukan dengan cara sebagai berikut :

1. Studi literature

Studi kasus dilakukan dengan mengambil data primer pada pembangunan rumah tinggal di citraland palu

2. Pengumpulan data

Dalam penelitian ini menggunakan data primer yaitu data yang diperoleh dari citraland palu

3. Menyusun jaringan kerja

Proses lengkap untuk menyusun jaringan kerja sebagai berikut :

a. Memberikan symbol pada setiap kegiatan

b. Menyusun rangkaian urutan kegiatan dengan menentukan bagian-bagian pekerjaan yang harus didahulukan dan pekerjaan yang harus menunggu setelah pekerjaan lain selesai.

c. Menentukan waktu pada setiap kegiatan, dalam penentuan waktu data diperoleh langsung dari citraland palu

4. Analisa data menggunakan metode Critical Path Method (Handoko.H,1994)

Proses tahapan dalam membuat lintasan kerja yaitu :

a. Menghitung waktu mulai paling awal kejadian i earliest start $(E S)_{i}$ dan selesai paling awal kejadian j earliest start $(E S)_{j}$.

b. Menghitung waktu paling akhir kejadian i Latest Finish $(L F) i$ dan selesai paling akhir kejadian j Latest Finish $(L F)_{j}$. 
5. Mencari probabilitas penyelesaian proyek menggunakan metode Project Evaluation and Review Technique (PERT) (Wijaya,2011)

Proses tersebut dilakukan dengan cara :

a. Menentukan waktu optimis, pesimis dan paling mungkin

b. Menghitung waktu yang diharapkan (te), standar deviasi $(\sigma)$ dan varians $(V)$ pada jalur kritis.

c. Menghitung probabilitas penyelesaian proyek pembangunan dengan waktu yang diharapkan.

\section{HASIL DAN PEMBAHASAN}

Pada penelitian ini akan ditentukan penyusunan diagram jaringan kerja proyek pambangunan rumah tinggal Tipe Belize pada perumahan Citraland Palu.

\subsection{Data Rancangan Kegiatan Proyek Pembangunan}

Data rancangan kegiatan proyek pembangunan rumah tinggal dapat dilihat pada tabel berikut :

Tabel 1 : Rancangan kegiatan proyek pembangunan rumah tinggal tipe belize

\begin{tabular}{|c|c|c|c|c|c|}
\hline No & Jenis Kegiatan (Pekerjaan) & $\begin{array}{l}\text { Simbol } \\
\text { Kegiatan }\end{array}$ & $\begin{array}{c}\text { Kegiatan } \\
\text { Sebelumnya }\end{array}$ & Waktu (Minggu) & Biaya (Rp) \\
\hline 1 & Pekerjaan Persiapan & A & - & 4 & $6.728 .809,00$ \\
\hline 2 & Pekerjaan Tanah & B & A & 2 & $12.099 .247,00$ \\
\hline 3 & Pekerjaan Pasangan dan Pondasi & C & B & 3 & $10.317 .857,00$ \\
\hline 4 & Pekerjaan Beton & $\mathrm{D}$ & C & 22 & $112.682 .835,00$ \\
\hline 5 & Pekerjaan Plesteran & $\mathrm{E}$ & $\mathrm{D}$ & 12 & $17.791 .922,00$ \\
\hline 6 & Pekerjaan Atap & $\mathrm{F}$ & $E$ & 16 & $21.714 .683,00$ \\
\hline 7 & Pekerjaan Mekanik dan Plumbing & G & $E$ & 2 & $17.150 .000,00$ \\
\hline 8 & Pekerjaan Listrik & $\mathrm{H}$ & $\mathrm{F}$ & 3 & $1.108 .000,00$ \\
\hline 9 & Pekerjaan Plafon & 1 & $\mathrm{H}$ & 2 & $55.465 .000,00$ \\
\hline 10 & $\begin{array}{l}\text { Pekerjaan Pelapis Lantai dan } \\
\text { Dinding }\end{array}$ & $\mathrm{J}$ & $E, F$ & 2 & $3.677 .101,00$ \\
\hline 11 & Pekerjaan Pintu dan Jendela & $\mathrm{K}$ & $\mathrm{J}$ & 2 & $2.016 .040,00$ \\
\hline 12 & Pekerjaan Finishing & L & $\mathrm{I}, \mathrm{K}$ & 2 & $23.985 .368,00$ \\
\hline 13 & Pekerjaan Sanitair & M & L & 3 & $13.150 .350,00$ \\
\hline \multicolumn{5}{|c|}{ Jumlah } & $297.887 .212,00$ \\
\hline
\end{tabular}

Sumber : Citraland Palu, 2016 


\subsection{Diagram Jaringan Kerja}

Berikut diagram jaringan perencanaan kerja :

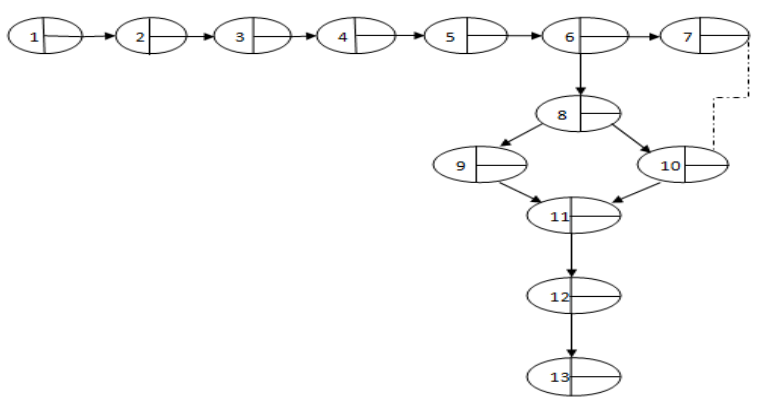

Gambar 1 : Diagram network perencanaan kerja

Tahapan berikutnya adalah menghitung lamanya pengerjaan proyek tersebut selesai berdasarkan tabel kegiatan dan diagram jaringan perencanaan proyek Jaringan kerja secara lengkap dari pengerjaan proyek sebagai berikut :

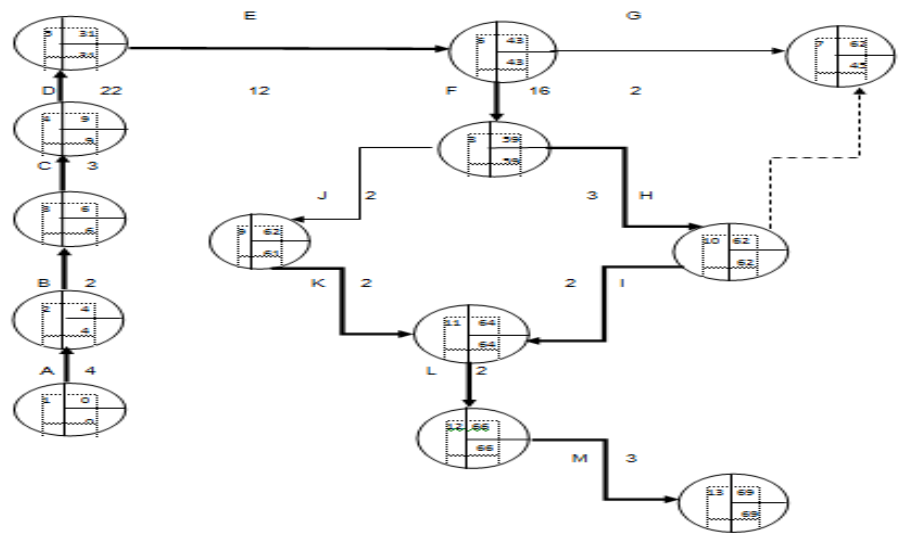

Gambar 2 : Diagram network jalur kritis dengan waktu penyelesaiannya.

\subsection{Lintasan Kerja}

Jalur kritis ini ditentukan dengan 2 cara yaitu perhitungan maju / perhitungan Earliest Start (ES) dan perhitungan mundur/ perhitungan Latest Finish (LF)

a. Perhitungan Earliest Start ( ES )

Perhitungan Earliest Start ( ES ) dapat di peroleh dari persamaan berikut :

$$
(E S)_{j}=(E S)_{i}+t
$$

Hasil dari perhitungan Earliest Start ( ES ) untuk setiap kegiatan diatas dapat dibentuk Tabel 2. 
Tabel 2 : Perhitungan Earliest Start ( ES )

\begin{tabular}{|c|c|c|c|c|c|}
\hline No & Jenis Kegiatan & Kegiatan Sebelumnya & $\mathrm{T}$ & $(E S)_{i}$ & $(E S)_{j}$ \\
\hline 1 & A & - & 4 & 0 & 4 \\
\hline 2 & B & A & 2 & 4 & 6 \\
\hline 3 & C & C & 3 & 6 & 9 \\
\hline 4 & D & D & 12 & 31 & 31 \\
\hline 5 & E & E & 16 & 43 & 59 \\
\hline 6 & F & E & 2 & 43 & 45 \\
\hline 7 & G & F & 3 & 59 & 62 \\
\hline 8 & H & H & 2 & 62 & 64 \\
\hline 9 & I & E,F & 2 & 59 & 61 \\
\hline 10 & J & J & 2 & 61 & 63 \\
\hline 11 & K & I,K & 2 & 64 & 66 \\
\hline 12 & L & M & 3 & 66 & 69 \\
\hline 13 & & & & & \\
\hline
\end{tabular}

Tabel 2 : menjelaskan bahwa dengan perhitungan maju membutuhkan waktu penyelesaian 69 minggu

b. Perhitungan Latest Finish (LF)

Perhitungan Latest Finish $(L F)$ dapat diperoleh dari persamaan berikut :

$$
(L F)_{i}=(L F)_{j}-t
$$

Hasil dari perhitungan Latest Finish (LF) untuk setiap kegiatan diatas dapat dibentuk tabel sebagai berikut :

Tabel 3 : Perhitungan Latest Finish (LF)

\begin{tabular}{|c|c|c|c|c|c|}
\hline No & Jenis Kegiatan & Kegiatan Sebelumnya & $(L F)_{i}$ & $\mathrm{~T}$ & $(L F)_{j}$ \\
\hline 1 & $\mathrm{M}$ & $\mathrm{L}$ & 69 & 3 & 66 \\
\hline 2 & $\mathrm{~L}$ & $\mathrm{I}, \mathrm{K}$ & 66 & 2 & 64 \\
\hline 3 & $\mathrm{~K}$ & $\mathrm{~J}$ & 64 & 2 & 62 \\
\hline 4 & $\mathrm{~J}$ & $\mathrm{H}$ & 62 & 2 & 60 \\
\hline 5 & $\mathrm{I}$ & $\mathrm{F}$ & 64 & 2 & 62 \\
\hline 6 & H & E & 62 & 3 & 59 \\
\hline 7 & G & E & 62 & 2 & 60 \\
\hline 8 & F & D & 59 & 16 & 43 \\
\hline 9 & E & C & 31 & 12 & 31 \\
\hline 10 & D & B & 9 & 3 & 9 \\
\hline 11 & C & A & 6 & 2 & 4 \\
\hline 12 & B & - & 4 & 4 & 0 \\
\hline 13 & A & & & 22 & 6 \\
\hline
\end{tabular}


Pada Tabel 3 menjelaskan bahwa dengan perhitungan mundur membutuhkan waktu penyelesaian proyek pembangunan 69 minggu.

\subsection{Jalur Kritis}

Kejadian kritis pada jaringan kerja memiliki tenggang waktu yang sama dengan persamaan slack yaitu $(E S)_{j}-(L F)_{i}=0$. Perhitungan kejadian kritis dapat dilihat dalam tabel sebagai berikut :

Tabel 4 : Perhitungan Kejadian Kritis

\begin{tabular}{|c|c|c|c|c|c|}
\hline No & Kegiatan & $(E S)_{J}$ & $(L F)_{i}$ & Float (slack) & Keterangan \\
\hline 1 & A & 4 & 4 & 0 & Jalur Kritis \\
\hline 2 & B & 6 & 6 & 0 & Jalur Kritis \\
\hline 3 & C & 9 & 9 & 0 & Jalur Kritis \\
\hline 4 & D & 31 & 31 & 0 & Jalur Kritis \\
\hline 5 & E & 43 & 43 & 0 & Jalur Kritis \\
\hline 6 & F & 59 & 59 & 0 & Jalur Kritis \\
\hline 7 & G & 45 & 62 & -17 & Bukan Jalur Kritis \\
\hline 8 & H & 62 & 62 & 0 & Jalur Kritis \\
\hline 9 & I & 64 & 64 & 0 & Bukan Jalur Kritis \\
\hline 10 & J & 61 & 62 & -1 & Jalur Kritis \\
\hline 11 & K & 64 & 64 & 0 & Jalur Kritis \\
\hline 12 & L & 66 & 66 & 0 & Jalur Kritis \\
\hline 13 & M & 69 & 69 & 0 & \\
\hline
\end{tabular}

Jalur kritis tersebut adalah kejadian 1, kegiatan A, kejadian 2, kegiatan B, kajadian 3, kegiatan $\mathrm{C}$, kejadian 4 , kegiatan $\mathrm{D}$, kejadian 5 , kegiatan $\mathrm{E}$, kejadian 6 , kegiatan $\mathrm{F}$, kejadian 8 , kegiatan $\mathrm{H}$, , kejadian 11, kegiatan I dan $\mathrm{K}$, kejadian 12, kegiatan $\mathrm{L}$, kejadian 13, kegiatan $\mathrm{M}$. Jumlah waktu yang diperlukan dalam proyek pembangunan adalah $(4+2+3+22+12+$ $16+3+2+3=69$ ).

\subsection{Alokasi Biaya Proyek}

Ciputra Surya Tbk untuk proyek pembangunan rumah tinggal Tipe Belize di perumahan Citraland Palu menghabiskan biaya proyek sebesar Rp. 297.887.212,00 ditambah gaji pekerja sebesar $25 \%$ dari total biaya proyek yaitu sebesar Rp. $74.471 .803,00$ sehingga total biaya proyek sebesar Rp. 372.359.015,00, data kegiatan yang dapat di Crashing merupakan persetujuan dari perusahaan yang bersangkutan yaitu proyek pembangunan perumahan Citraland Palu. 


\subsection{Proses Crashing}

Analisa proses Crashing dari beberapa kegiatan yang melewati jalur kritis pada rancangan proyek pembangunan. Rumus umum untuk menyelesaikan Crashing adalah :

$$
\text { Crashing per minggu }=\frac{\text { Biaya dipercepat }- \text { Biaya normal }}{\text { waktu normal }- \text { waktu cepat }}
$$

Hasil dari perhitungan rumus di atas dapat dibentuk tabel sebagai berikut :

Tabel 5 : Perhitungan Crashing

\begin{tabular}{|c|c|c|c|c|c|c|}
\hline \multirow{2}{*}{ Kegiatan } & \multicolumn{5}{|c|}{ Waktu } & \multicolumn{2}{c|}{ Biaya } & \multirow{2}{*}{$\begin{array}{c}\text { Biaya Crashing } \\
\text { Perminggu }\end{array}$} \\
\cline { 2 - 6 } & Normal & Crashing & Percepatan & Normal & Crashing & 1.682 .202 \\
\hline A B & 4 & 3 & 1 & 6.728 .809 & 8.411 .011 & - \\
\hline C & 2 & 2 & 0 & 12.099 .247 & - & 2.579 .464 \\
\hline D & 22 & 15 & 1 & 10.317 .857 & 12.897 .321 & 4.024 .387 \\
\hline E & 12 & 10 & 2 & 17.791 .922 & 22.239 .902 & 2.223 .990 \\
\hline F & 16 & 10 & 6 & 21.714 .683 & 27.143 .353 & 904.778 \\
\hline G & 2 & 2 & 0 & 17.150 .000 & - & - \\
\hline H & 3 & 2 & 1 & 1.108 .000 & 1.385 .000 & 277.000 \\
\hline I & 2 & 2 & 0 & 55.465 .000 & - & - \\
\hline J & 2 & 2 & 0 & 3.677 .101 & - & - \\
\hline K & 2 & 1 & 1 & 2.016 .040 & 2.520 .050 & 504.010 \\
\hline L & 2 & 1 & 1 & 23.985 .368 & 29.981 .710 & 5.996 .342 \\
\hline M & 3 & 1 & 2 & 13.150 .350 & 16.437 .937 & 1.643 .794 \\
\hline
\end{tabular}

Pada Tabel 5 kegiatan jalur kritis tersebut yaitu kegiatan $\mathrm{F}$ (pekerjaan atap), kegiatan $\mathrm{H}$ (pekerjaan listrik), dan kegiatan $\mathrm{K}$ (pekerjaan pintu dan jendela), merupakan kegiatan yang memiliki biaya crashing perminggu yang paling minimum dari beberapa kegiatan yang ada.

Dari hasil perhitungan crashing diperoleh jalur kritis sebagai berikut :

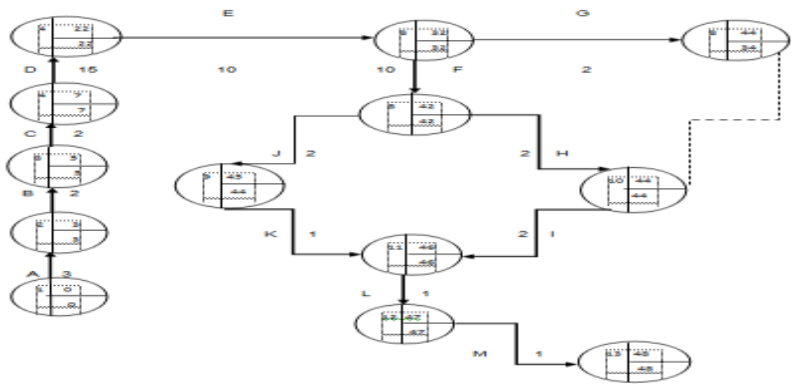

Gambar 3 : Diagram Jaringan Kerja setelah di crashing 
Total waktu yang diperlukan untuk proyek pembangunan rumah tinggal Tipe Belize perumahan Citraland Palu setelah di crashing yaitu 48 minggu dengan total biaya yang harus dikeluarkan yaitu :

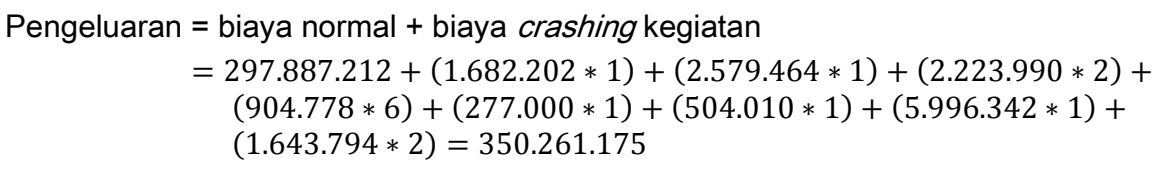

Total biaya proyek pembangunan rumah tinggal perumahan Citraland Palu Tipe Belize setelah dilakukan crashing yaitu sebesar $R p .350 .261 .175,00$

Kegiatan proyek pembangunan dengan waktu normal membutuhkan waktu 69 minggu dengan biaya total $R p .297 .887 .212,00$ ternyata kegiatan proyek bisa dipercepat menjadi 48 minggu dengan biaya total sebesar $R p .350 .261 .175,00$.

Perbandingan keuntungan perusahaan selama 96 minggu (2 tahun) sebelum dicrashing dengan total biaya pengeluaran selama 69 minggu untuk 1 unit bangunan rumah adalah sebesar Rp.297.887.212,00 yang dijumlahkan dengan total biaya interior sebesar $R p .870 .000 .000,00$, dimana harga jual telah ditentukan sebesar $R p .2 .150 .000 .000,00$, maka didapatkan keuntungan untuk 1 unit rumah dalam 69 minggu adalah $R p .982 .112 .788,00$. Sedangkan total biaya pengeluaran selama 96 minggu untuk 2 unit bangunan rumah adalah sebesar $R p .700 .522 .350,00$ yang di jumlahkan dengan total biaya interior sebesar $R p .1 .740 .000 .000,00$, maka didapatkan keuntungan untuk 2 unit bangunan rumah dalam 96 minggu (2 tahun) adalah sebesar $R p \cdot 2.729 .477 .650$. Dengan demikian perbandingan hasil keuntungan yang diperoleh setelah di crashing sebesar $R p .1 .859 .447 .650$.

Perusahaan dalam mengerjakan proyek dengan waktu normal dapat menyelesaikan rumah selama 96 minggu (2 tahun) yaitu 1 unit rumah, setelah dilakukan crashing perusahaan dapat menyelesaiakan 2 unit rumah selama 96 minggu ( 2 tahun) dengan biaya pembangunan yang tidak jauh berbeda. Perusahaan dengan menyelesaiakn 2 bangunan rumah selaha 96 minggu akan mendapatkan keuntungan yang lebih besar.

\subsection{Probabilitas Penyelesaian Rancangan Proyek Pembangunan}

Probabilitas penyelesaian rancangan proyek pembangunan menggunakan metode Program Evolution and Review Technique (PERT). Dalam penelitian ini kegitan yang digunakan adalah kegiatan secara garis besar, jadi untuk mencari nilai optimis dan pesimisnya dapat dicari terlebih dahulu standar waktunya yaitu dengan menggunakan rumus sebagai berikut :

$$
\sigma=\sqrt{\frac{\sum(x-\bar{x})^{2}}{N-1}}
$$


Setelah ketiga estimasi waktu telah diperoleh, maka ekspektasi waktu (waktu yang diharapkan ) dari masing-masing kegiatan juga dapat ditentukan dengan cara :

$$
t e=\frac{t o+4 . m+t p}{6}
$$

Untuk menghitung disperse (dispersion) atau varians waktu penyelesaian kegiatan (variance of activity time), dapat digunakan rumus :

$$
v e=\left[\frac{(t p-t o)}{6}\right]^{2}
$$

\begin{tabular}{|c|c|c|c|c|c|c|}
\hline \multirow{2}{*}{ Kegiatan } & \multicolumn{3}{|c|}{ waktu } & \multirow{2}{*}{$\mathrm{Te}$} & \multirow{2}{*}{ ve } & \multirow{2}{*}{ keterangan } \\
\hline & $\mathrm{m}$ & to & tp & & & \\
\hline A & 4 & 4.868457 & 3.131543 & 4 & 3.01687 & JK \\
\hline B & 2 & 2.692308 & 1.307692 & 2 & 1.91716 & JK \\
\hline C & 3 & 3.307692 & 2.692308 & 3 & 0.378698 & JK \\
\hline$D$ & 22 & -14.2308 & 58.23077 & 22 & 5250.675 & JK \\
\hline E & 12 & 1.923077 & 22.07692 & 12 & 406.1775 & JK \\
\hline $\mathrm{F}$ & 16 & -2.69231 & 34.69231 & 16 & 1397.609 & JK \\
\hline G & 2 & 2.692308 & 1.307692 & 2 & 1.91716 & BJK \\
\hline $\mathrm{H}$ & 3 & 3.307692 & 2.692308 & 3 & 0.378698 & JK \\
\hline 1 & 2 & 2.692308 & 1.307692 & 2 & 1.91716 & JK \\
\hline $\mathrm{J}$ & 2 & 2.692308 & 1.307692 & 2 & 1.91716 & BJK \\
\hline K & 2 & 2.692308 & 1.307692 & 2 & 1.91716 & JK \\
\hline L & 2 & 2.692308 & 1.307692 & 2 & 1.91716 & JK \\
\hline M & 3 & 3.307692 & 2.692308 & 3 & 0.378698 & JK \\
\hline Jumlah & 69 & 15.945348 & 134.05462 & 69 & $7066.2831 / 36$ & \\
\hline
\end{tabular}

Tabel 7 : Perhitungan waktu yang diharapkan dan varians rancangan proyek

Dari hasil perhitungan diatas diperoleh nilai varians waktu penyelesaian proyek berdasarkan lintasan kritis adalah sebesar 7066.2831/36 atau 196.28564

dengan standar deviasi adalah $\sqrt{196.28564}=14.010198$ minggu. Perhitungan probabilitas proyek pembangunan yang menghabiskan waktu selam 48 minggu dengan rumus sebagai berikut :

$$
Z=\left[\frac{\text { batas waktu }- \text { waktu yang diharapkan }}{\text { standard deviasi }}\right]=1.49
$$

Pada tabel kurva normal dapat dikonversikan $Z=1.49$ adalah sama dengan $0.9319=93.19 \%$. Jadi besarnya probabilitas proyek dapat diselesaikan dalam waktu 48 minggu adalah sebesar $93.19 \%$. 


\section{KESIMPULAN}

Berdasarkan penelitian yang telah dilakukan maka disimpulkan bahwa :

1. Penyusunan diagram jaringan kerja pada proyek pembangunan rumah tinggal diperumahan citraland palu dengan menggunakan metode CPM-PERT adalah sebagai berikut :

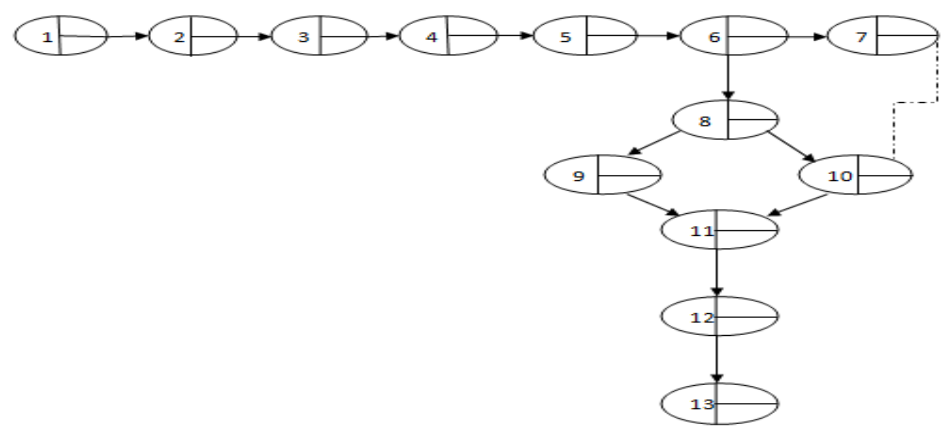

2. Hasil perhitungan proyek pembangunan menggunakan Critical Path Method (CPM) menghasilkan waktu penyelesaian proek selama 69 minggu dengan total biaya sebesar $R p$.297.887.212.00 setelah dilakukan pengoptimalan waktu dengan meng crashing setiap kegiatan pelaksanaan pembangunan tersebut menjadi 48 minggu dengan total biaya $R p .350 .261 .175 .00$. Waktu penyelesaian lebih cepat dibandingkan kegiatan normal yang dilakukan dengan biaya yang optimal. Dari probabilitas penyelesaian rancangan proyek pembangunan menggunakan metode Program Evolution and Review Technique (PERT) besar peluang untuk terselesaikannya pekerjaan proyek selama 48 minggu adalah sebesar $93.19 \%$ 


\section{DAFTAR PUSTAKA}

[1]. Ade Saparudin, Optimalisasi Biaya dan Waktu Pelaksanaan Proyek Pembangunan Rumah Tinggal Dengan Menggunakan Metode PERT - CPM, 2014

[2]. Aryo Andri Nugraho, Optimalisasi Penjadwalan Proyek Pada Pembangunan Gedung Khusus (Laboratorium) Stasiun Karantina Ikan Kelas 1 Tanjung Mas Semarang, 2007

[3]. Britama,Britama,Sejarah dan Profil Singkat Ctrs (Ciputra Surya Tbk), 2012, 2014,http://www.britama.com/index.php/2012/10/sejarah-dan-profil-singkat-ctrs, diakses pada tangggal 20 januari 2016 pukul 14.00 Wita

[4]. Handoko. H, Dasar-Dasar Manajemen Produksi Dan Operasi, BPFE, 1994, Yogyakarta

[5]. Kusnanto, Penjadwalan Proyek Konstruksi Dengan Metode Pert (Studi Kasus Proyek Pembangunan Gedung R.Kuliah Dan Perpustakaan Pgsd Kleco Fkip Unstahap I), 2010

[6]. Muhammad Rizki Ridho, Syahrizal, Evaluasi penjadwalan waktu Dan Biaya Proyek Dengan Metode Pert dan Cpm, 2014, Jurnal.USU.ac.id/index.php.Jts/artict/view File $16294 / 2659$

[7]. Wijaya, Pengantar Riset Operasi. Mitra Wacana Media, 2011, Jakarta 